\title{
Comparative Study on Janus Kinase Enzyme activity of Pomegranate Leaf Extract and its Active Component Ellagic Acid for Asthma
}

\author{
SARITHAMOL S ${ }^{1}$, V. L. PUSHPA*1 and K. B. MANOJ ${ }^{1}$ \\ ${ }^{1} \mathrm{P}$ G and Research Department of Chemistry, Sree Narayana College, Kollam, Kerala 691001, India. \\ ${ }^{*}$ Corresponding author E-mail: drpushpavl2017@gmail.com
}

http://dx.doi.org/10.13005/ojc/340255

(Received: October 13, 2017; Accepted: January 10, 2018)

\begin{abstract}
Asthma is the most severe condition of lung airway inflammatory cells. Two third of asthmatic patients are nonresponsive towards existing treatments. The present study has focused on potency of IL4-JAK1-STAT6 signaling pathway as an investigational therapeutic target for the disease. Pomegranate plant is well studied for its potential phytochemicals. The therapeutic efficiency of pomegranate plant leaves and its active component ellagic acid against the signaling pathway has been investigated. The quantitative estimation of ellagic acid in the aqueous alcoholic extract of pomegranate leaves was done. Cell toxicity of ellagic acid and plant leaf extract was checked on macrophage raw cells using MTT assay and their activity against JAK1 enzyme were found out by ELISA method. The result signifies that pomegranate leaf extract is more efficient than ellagic acid towards JAK1 enzyme. Therefore the present study has highlighted the potency of pomegranate leaf extract over ellagic acid, the active component, for the disease asthma through IL4-JAK1-STAT6 pathway.
\end{abstract}

Keyword: Asthma, JAK1-STAT6 pathway, Phytochemical extraction, HPLC, MTT assay, Activity assay.

\section{INTRODUCTION}

Asthma is a multi targeted anti-inflammatory lung disorder controlled by different type of pathways and proteins. Protein kinases are dominant class of targets for autoimmune diseases like asthma ${ }^{1}$. Inhibitors of protein kinases were established as effective drugs for asthma². Corticosteroids, bronchodilators are some popular drugs in the market. Majority of asthma patients were nonresponsive towards those medications ${ }^{3}$. Cytokines are a category of potential targets for asthma. Their abnormal quantity during asthma attack made them to consider as potential targets 4 . Among the cytokines, interleukin 4, interleukin 5, interleukin 10, interleukin 13, interleukin 12 were identified as significant targets for the disease pathogenesis. After producing IL4 and IL13 by

This is an 2 Open Access article licensed under a Creative Commons Attribution-NonCommercial-ShareAlike 4.0 International License (https://creativecommons.org/licenses/by-nc-sa/4.0/ ), which permits unrestricted NonCommercial use, distribution and reproduction in any medium, provided the original work is properly cited. 
eosinophils and basophils, they get migrated to the inflammation site and produce mucus and immunoglobulin $\mathrm{E}$, agents create problem while breathing. These cytokines communicate with their receptors through the cell surface and initiate the signaling process of janus kinase-signal transducer and activation of transcription pathways (JAK1-STAT6 pathways) $^{5}$. The present study has focused on IL4-IL4R signaling JAK1-STAT6 pathway. IL4 is an important biological target for the personalized treatment of asthma. janus kinase is one among the non receptor tyrosine kinase family is capable of initiating several signaling pathways including activation of signal transducer and activation of transcription (STAT) in mast cells, T cell, $B$ cells, macrophages etc ${ }^{6}$. JAK family members include JAK1, JAK2, JAK3 and TYK2 and STAT family include STAT1 to 6 and STAT5A and 5B proteins. During the attack of allergens, cytokine communicate with its receptor, followed by the activation of JAKs. The activated JAKs phosphorylate specific tyrosine groups in the cytoplasmic region of cytokine receptor subunit. Those region then binds with stats. The docking of stat with tyrosine phosphorylated receptor subunit of IL4; they get phosphorylated by the activation of associated JAKs. The phosphorylated stat then detached from the receptor subunit, dimerises and get migrated to the nucleus, there it cause gene transcription associated with asthma. Inhibiting the cytokine signaling pathway by suitable JAK inhibitors is highly recommended. The mechanism behind the inhibition is as follows. The active site of JAK is furnished by binding of an ATP (adenosine triphosphate) unit. One way of inhibition is that the inhibitor can behave as an ATP competitive inhibitor there by blocking the ATP binding to the catalytic cleft of JAK, followed by the deactivation $\mathrm{JAKs}^{7}$. The deactivated JAKs will never go for completion of the IL4 signaling pathway. Therefore JAK1-STAT6 signaling pathway inhibition in association with IL4-IL4R signaling can create an effectual result in the disease treatment. Nature is a rich source of compounds with high therapeutic potential ${ }^{8}$. Plant world is an amazing example for it. Flavonoids, polyphenols and terpenes are some among the potential compounds. There are large variety of phytochemicals those having negative influence in the JAK1-STAT6 signaling pathway ${ }^{9}$. Anti-inflammatory phytochemicals such as flavonoids and curcuminoids are very good responsive towards JAK1. Present study focused on the therapeutic potential of one of the promising plants, pomegranate (Punica granatum L., Punicaceae) against JAK1 enzyme ${ }^{10}$. Pomegranate plant is well appreciated for its antioxidant, anti-inflammatory anti cancerous properties. Its fruit, flower, bark, leaf etc. have independent therapeutic potential ${ }^{11}$. Here we are investigating the therapeutic effect of pomegranate leaf extract over its active principle, ellagic acid. The anti-inflammatory effect of aqueous alcoholic extract of leaves of pomegranate is due to the presence of ellagic acid as the major constituent. The present study focused on investigating whether ellagic acid or the extract is more active towards JAK 1 enzyme through invitro assay.

\section{MATERIALS AND METHODS}

\section{Materials}

Ellagic acid (HPLC grade) purchased from Sigma Aldrich, JNK activity assay kit, Kinase star purchased from RayBiotech, Inc., RAW 264.7 cells was purchased from National Centre for Cell Sciences (NCCS), Pune, India and maintained Dulbecos modified Eagles medium (Gibco, Invitrogen), MTT (Sigma, M-5655).

\section{Extraction}

Pomegranate leaves were collected locally and dried inthe shade at $40^{\circ} \mathrm{C}$ after washed well with running water. The dried material then ground into powder. The powder $(10 \mathrm{~g})$ was macerated with $70 \%$ aqueous alcohol[70:30=alcohol: water] $(100 \mathrm{ml})$ at room temperature for seven days with occasional agitation. The extract was concentrated using rotary evaporator, dried under vacuum and stored at $-80{ }^{\circ} \mathrm{C}$ until use ${ }^{12}$.

\section{HPLC analysis of extract}

The extract was subjected to HPLC analysis for the quantification of ellagic acid in it. For the analysis, C-18 ODS2 HPLC column with diameter 5 micrometer and dimension $4.6 \times 150 \mathrm{~mm}$ associated with a UV detector was orchestrated. The analysis was performed at a flow rate of $0.8 \mathrm{ml} / \mathrm{min}$. mobile phase consisted of acetonitrile (A)/O-phosphoric acid (0.3\%) in water (B). Absorbance was measured at a frequency of $254 \mathrm{~nm}$. Ellagic acid from the extract was estimated 
quantitatively using the pure ellagic acid as reference.

\section{In vitro analysis}

The aqueous alcoholic extract and ellagic acid were subjected to in vitro analysis with JAK 1 enzyme after checking their cytotoxicity towards RAW 264.7 macrophage cells using MTT assay. The procedure was as follows ${ }^{13}$

Different quantity of extract and ellagic acid $(6.25,12.5,25,50,100 \mu \mathrm{g} / \mathrm{mL})$ were incubated with seeded cells in 96 well plate at $1 \times 10^{4}$ cells/well in the culture medium at $37^{\circ} \mathrm{C}$ in a humidified $5 \%$ $\mathrm{CO}_{2}$ incubator for 24 hours. After adding $15 \mathrm{mg}$ of MTT, (3-(4,5-Dimethylthiazol-2-yl)-2,5-Diphenyltetrazolium Bromide), the system was subjected for $10 \mathrm{~min}$. incubation and the absorbance was measured using microplate reader at a wavelength of $540 \mathrm{~nm}$. Results were produced by comparing with the percentage of untreated control. Any change in the morphology of the cells can be treated as cell toxicity.

\section{Enzyme activity assay}

LPS stimulated macrophage raw cells 264.7 , were incubated with $100 \mu \mathrm{l}$ of leaf extract and ellagic acid at their maximum cell viable concentration for $37{ }^{\circ} \mathrm{C}$ overnight. After treatment with $200 \mu \mathrm{l}$ of blocking buffer (Composition-0.2\% gelatin in $0.05 \%$ tween 20 in PBS), the system was incubated at room temperature for $1 \mathrm{~h}$. $100 \mu \mathrm{l}$ primary antibody (JNK Specific antibody) was added and kept it for $2 \mathrm{~h}$ followed by treating with secondary antibody $(100 \mu \mathrm{l})$ for $1 \mathrm{~h}$ at room temperature. Finally $200 \mu \mathrm{l}$ of $\mathrm{O}$-dianizdine (Composition-1 mg o-ianizdine/100 $\mu$ l methanol $+21 \mathrm{ml}$ citrate buffer $+60 \mathrm{ml}$ hydrogen peroxide) was added and after 30 min. stopped the reaction by adding $5 \mathrm{~N} \mathrm{HCl}(50 \mu l)$. Read the absorbance at $415 \mathrm{~nm}$.

\section{RESULT AND DISCUSSION}

\section{HPLC analysis}

HPLC analysis on aqueous alcoholic extract of pomegranate leaves was carried out to quantify the ellagic acid in the extract. On examining the chromatogram in Fig 1, it was found that retention time corresponds to 10ppm of standard ellagic acid was 15.521 and that of $\mathrm{X} \mathrm{ppm}$ of ellagic acid in plant extract was 15.421 , the area under the peak of the standard sample was 922020 while that in the extract was 4857019. The amount of extract taken for HPLC analysis was $0.01 \mathrm{~g}$. The amount of ellagic acid in the extract can be quantified as follows

10 ppm / X = $922020 / 4857019$

$X$, quantity of the ellagic acid in the extract $=(10 x$ 4857019) / 922020

$$
\begin{aligned}
& =(52.67802 / 0.01) \times 10 \\
& =52678.022 \mathrm{ppm}=5.2678 \% . \\
& =52.678 \mathrm{~g} / \mathrm{Kg}
\end{aligned}
$$

The quantity of ellagic acid in the pomegranate leaf aqueous alcoholic extract was found to be $5.267 \%(52.678 \mathrm{~g} / \mathrm{Kg})$. Ellagic acid is identified as the most significant therapeutic constituent of pomegranate plant. Through the present study, we are analyzing whether ellagic acid alone or extract as such is more significant for the JAK1 enzyme inhibition.
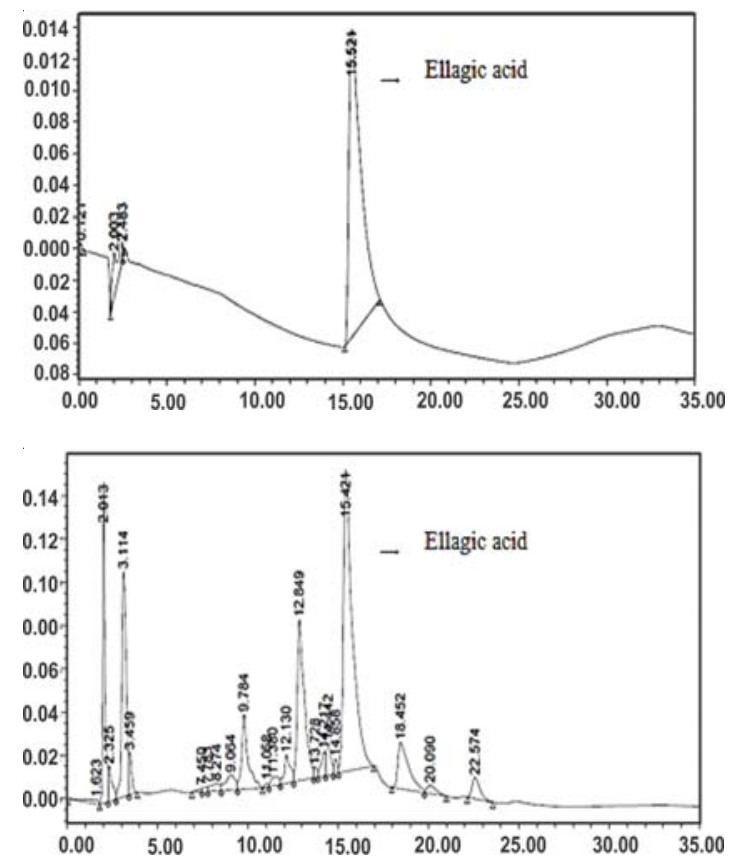

Fig. 1. HPLC Chromatogram of Pure Ellagic Acid and Plant Extract. First Figure Represents Chromatogram Of Ellagic Acid And Second Represents Plant Extract 
In vitro analysis on aqueous alcoholic extract of pomegranate leaves and ellagic acid

In vitro studies were conducted on the leaf extract and ellagic acid against JAK1 enzyme. Before that, the toxicity of extract and ellagic acid towards macrophage raw cells were checked. The toxicity studies of leaf extract and ellagic acid is explained as follows.

MTT assay for plant leaf extract (aqueous alcoholic extract) and ellagic acid

$1 \mathrm{mg}$ of the dried leaf extract and ellagic acid were subjected to cytotoxicity studies on macrophage raw cells and the result is shown in the Fig. 2 and Fig. 3.
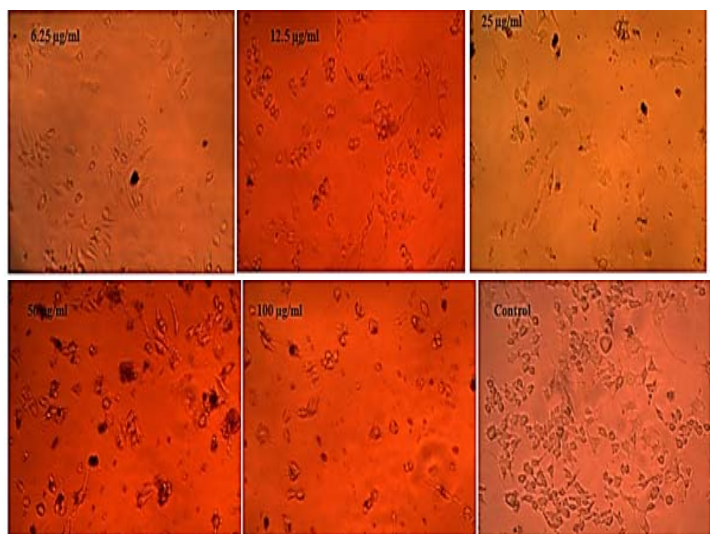

Fig. 2. Cell Viability Images of Aqueous Alcoholic Extract of Pomegranate Leaf
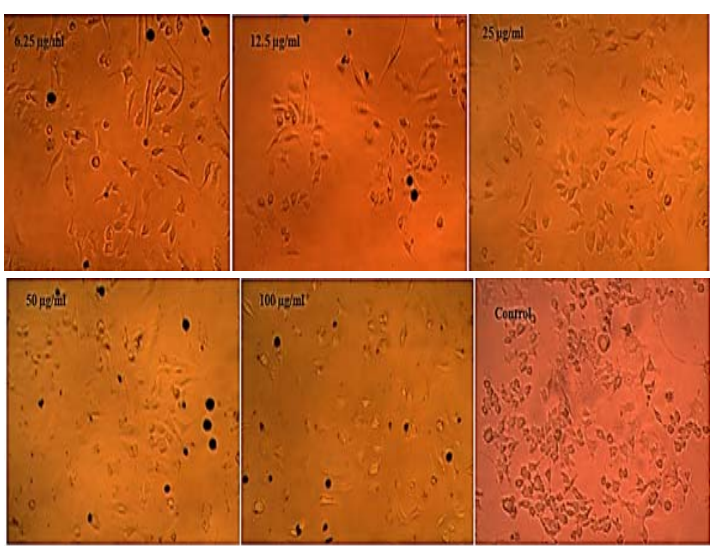

Fig. 3. Cell Viability Images of Ellagic Acid on Macrophage Raw Cells

The Fig. 2 and 3 gave clear information on the cyto toxicity of the leaf extract and ellagic acid. The maximum cell viability is observed only at lesser concentration of them. As the concentration increases, toxicity created by both the system increases. The cell viability is displayed in Table 1. From the findings, the LD90 (concentration required for $90 \%$ viable cells) of extract was calculated as $0.1004 \mu \mathrm{g}$ and ellagic acid as $2.686 \mu \mathrm{g} / \mathrm{ml}$ (using the excel based statistical software LD50 plus). Fig. 4 compares the toxic effect of leaf extract and ellagic acid

\begin{tabular}{lcc}
$\begin{array}{c}\text { Table 1: Percentage Viability of Cells In } \\
\text { Response With Varying Concentration Of } \\
\text { Plant Extract And Ellagic Acid }\end{array}$ \\
$\begin{array}{l}\text { Concentration } \\
\text { C } \\
(\mu \mathrm{g} / \mathrm{mL})\end{array}$ & $\begin{array}{c}\text { \% viability } \\
\text { Conic acid }\end{array}$ & Leaf extract \\
\hline control & 100 & 100 \\
6.25 & 73.86 & 75.3 \\
12.5 & 68.15 & 60.36 \\
25 & 68.23 & 56.99 \\
50 & 57.62 & 56.82 \\
100 & 49.92 & 46.12 \\
\hline
\end{tabular}

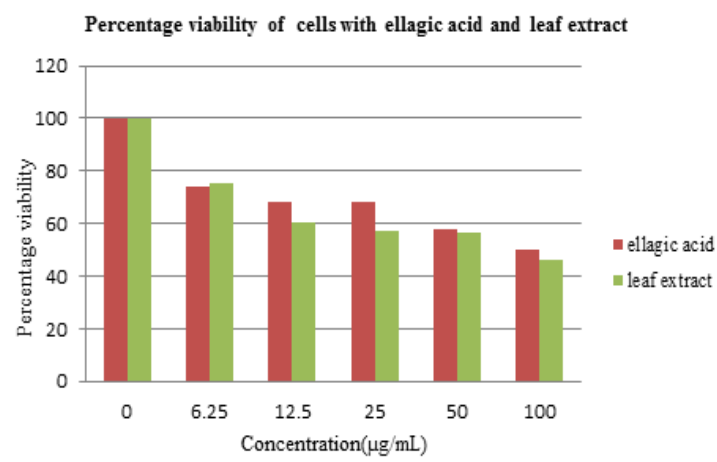

Fig. 4. Cell Toxicity Effects of Ellagic Acid and Leaf Extract On Raw Macrophage Cells

\section{Enzyme activity assay}

$100 \mu \mathrm{l}$ of leaf extract $(0.1004 \mu \mathrm{g})$ and ellagic $\operatorname{acid}(2.686 \mu \mathrm{g})$ were subjected to activity assay with LPS induced macrophage raw cells and the percentage activity of both the samples were measured against JAK1 enzyme using JAK 1 specific antibody by indirect ELISA method. The percentage activity of extract towards JAK1 at $0.1004 \mu \mathrm{g}$ concentration was found to be $66.53 \%$ while that of ellagic acid at $2.686 \mu \mathrm{g}$ concentrations was found as $75.91 \%$ (Table 2 ). The result signifies potency of leaf extract over the active principle, ellagic acid. 
Table 2: Concentration At $90 \%$ Cell Viable Condition of Macrophage Cells And Corresponding Activity Of Ellagic Acid And Leaf Extract

\begin{tabular}{lcc}
\hline Parameters & Ellagic acid & Leaf extract \\
\hline Concentration $(\mu \mathrm{g})$ & 2.97 & 0.1004 \\
Percentage activity & 75.91 & 66.53 \\
\hline
\end{tabular}

Statistical significance of activity percentage data, student $t$ test, $p<0.005$. Readings of data are average of three experiments.

activity- concentration chart

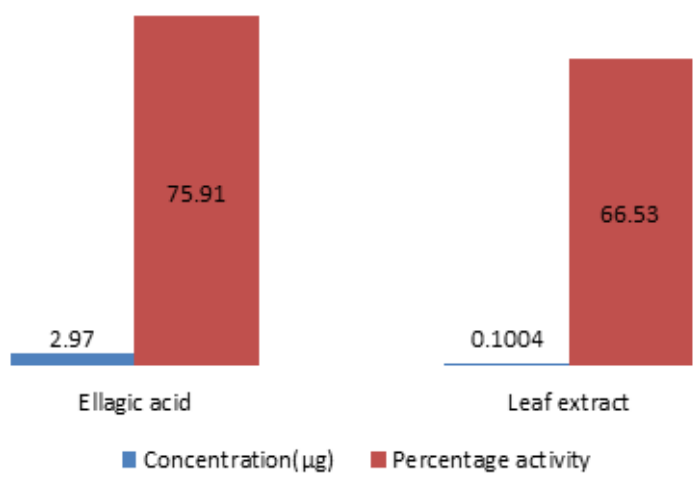

Fig. 5. JAK1 Activity-Concentration Comparisons of Leaf Extract Vs Ellagic Acid

The chart (Fig. 5) shows that leaf extract is more efficient than the independent component ellagic acid as JAK 1 inhibitor. The activity of leaf extract was found to be more than that of ellagic acid. The result is displayed in Table 2 . The findings signify the importance of extract as a better anti-inflammatory agent against JAK1. Therefore, the extract itself can be suggestively used for JAK1 driven immunomodulatory diseases like asthma, allergy, rheumatoid arthritis etc.

\section{CONCLUSION}

Pomegranate leaf extract and its active principle ellagic acid has compared for its activity against JAK1 enzyme which is a well-studied potential target for the disease asthma. A better inhibitor of JAK 1 is able to act as a therapeutic agent for the disease. HPLC analysis quantifies the ellagic acid in the extract as $5.2678 \%(52.678 \mathrm{~g} / \mathrm{Kg})$. MTT assay has revealed the cytotoxicity of leaf extract and ellagic acid against raw macrophage cells and both the systems were exhibiting better cell viability at lower concentrations. The percentage activity of both the samples against JAK1 enzyme was found to be $75.91 \%$ for ellagic acid and $66.53 \%$ for leaf extract.The final result has highlighted the potency of leaf extract over the active principle ellagic acid as better JAK 1 inhibitor. This signifies the effectiveness of combination of potential compounds over individual ones. This inhibitory property can be making use of for designing drugs for asthma.

\section{ACKNOWLEDGEMENT}

The authors are deeply indebted to 'The University of Kerala' for providing research fellowship. We express our genuine gratitude to 'Sree Narayana College, Kollam', Kerala for providing facilities as a research centre.

\section{REFERENCE}

1. Adcock, I.M.; Caramori, G.; Chung, K. F.; Lancet., 2008,372, 1073-1087.

2. Hernández-flórez, D.; Valor, L.; Reum Clin., 2017, 12, 91-99.

3. Barnes, P.J.; J Allergy Clin Immunol [Internet]., 2015, 136, 531-545.

4. Szabo, E.; Kovacs, I.; Grune, T.; Haczku, A.; Virag, L.; Eur J Allergy Clin Immunol., 2011, 66, 811-814.

5. Shuai, K.; Liu, B.; www.nature.com/reviews/ immunol. 2003, 3, 900-911.

6. Wong, W. S. F.; Pang, K.; Biochimica et Biophysica Acta., 2004,1697, 53-69.

7. Hodge, J.A.; Kawabata,T.T.; Krishnaswami, S.; Clark, J.D.; Telliez, J.B.; Dowty, M.E.;
Menon, S.; Lamba, M.; Zwillich, S.; Clin Exp Rheumatol., 2016, 34, 318-328.

8. Tanaka, T.; Takahashi, R.; Nutrients., 2013, 5, 2128-2143.

9. Chen, S.; Curr Drug Targets [Internet]., 2011, 12, 288-301.

10. Mohammad, S.M.; Kashani, H.H.; J Med Plants Res., 2012, 6, 5306-5310.

11. Yoshimura, M.; Watanabe, Y.; Kasai, K.; Yamakoshi, J.; Biosci Biotechnol Biochem., 2014, 8451, 2368-2373

12. Chanda, S.V.; Food Anal. Methods., 2012, 5 ,396-404.

13. Dinesh, M.D.; Athira, P.S.; Ajma, N.; Abhisha, N.C.; Carmel, A.; Int J Life Sci Sci Res., 2016, 2, 412-414. 